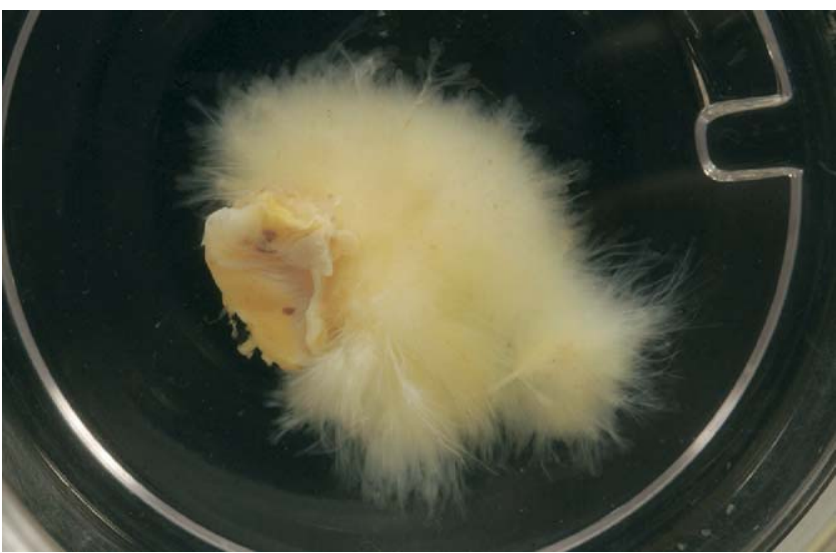

Figure 2. Papillary fibroelastoma excised with $2-\mathrm{cm}$ disk around stalk.

725 cases, in $84 \%$ of the cases the valvular surface was the predominant location of the tumor. ${ }^{2}$ Nonvalvular location is rare, and just 2 cases have been reported to involve the right atrium. ${ }^{6}$
This is the first report of a cardiac papillary fibroelastoma originating from pectinate muscles of the right atrial free wall.

\section{Conclusion}

Right atrial cardiac papillary fibroelastoma is an extremely rare finding. Only 2 cases have been previously reported in the literature. This is the first report of such a tumor attached to the pectinate muscles of the right atrial free wall.

\section{References}

1. Edwards FH, Hale D, Cohen A, Thompson L, Pezzella AT, Virmani R. Primary cardiac valve tumors. Ann Thorac Surg. 1991;52:1127-31.

2. Gowda RM, Khan IA, Nair CK, Mehta NJ, Vasavada BC, Sacchi TJ. Cardiac papillary fibroelastoma: a comprehensive analysis of 725 cases. Am Heart J. 2003;146:404-10.

3. Chartier L, Béra J, Delomez M, Asseman P, Beregi JP, Bauchart J, et al Free-floating thrombi in the right heart: diagnosis, management, and prognostic indexes in 38 consecutive patients. Circulation. 1999;99: 2779-83.

4. Panidis IP, Kotler MN, Mintz GS, Ross J. Clinical and echocardiographic features of right atrial masses. Am Heart J. 1984:107:745-58.

5. Reynen K. Cardiac myxomas. N Engl J Med. 1995;333:1610-7.

6. Schiller AL, Schantz A. Papillary endocardial excrescence of the right atrium: report of two cases. Am J Clin Pathol. 1970;53:617-21.

\title{
Accessory mitral valve causing left ventricular outflow tract obstruction and mitral insufficiency
}

Hiroshi Tanaka, MD, Kenji Okada, MD, Teruo Yamshita, MD, Keitaro Nakagiri, MD, Masamichi Matsumori, MD, and Yutaka Okita, MD, Kobe, Japan

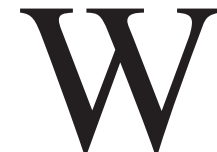

e report a case of accessory mitral valve that caused both left ventricular outflow tract (LVOT) obstruction and mitral insufficiency. This was treated surgically with excision of the accessory mitral valve, septal myectomy, and mitral annuloplasty. This is a rare case in which the accessory mitral valve caused both LVOT obstruction and mitral insufficiency describing the detail of the pathology.

\footnotetext{
Kobe University Hospital, Department of Cardiovascular, Thoracic, and Pediatric Surgery, Kobe, Japan.

Received for publication Jan 15, 2006; accepted for publication Jan 20, 2006.

Address for reprints: Hiroshi Tanaka, MD, Kobe University Hospital, Department of Cardiovascular, Thoracic, and Pediatric Surgery, 7-5-2, Kusunoki-cho, Chuo-ku, Kobe, Japan (E-mail: hirot@ams.odn.ne.jp).

J Thorac Cardiovasc Surg 2006;132:160-1

$0022-5223 / \$ 32.00$

Copyright $\odot 2006$ by The American Association for Thoracic Surgery doi:10.1016/j.jtcvs.2006.01.062
}

\section{Clinical Summary}

A 65-year-old man was referred to us for the diagnosis of moderate aortic insufficiency, moderate mitral insufficiency, and an abnormal structure in the LVOT. The electrocardiogram showed left ventricular hypertrophy and frequent ventricular arrhythmias. Transesophageal echocardiography demonstrated subaortic obstruction of the LVOT (Figure 1) (moderate aortic insufficiency, septal hypertrophy, and moderate mitral insufficiency), which was supposed to be caused by a cleft in the anterior mitral leaflet. The mean pressure gradient across the LVOT was $43 \mathrm{~mm} \mathrm{Hg}$.

At surgery, the aortic valve was tricuspid, with a large fenestration at the left coronary cusp-right coronary cusp commissure portion. There was an abnormal structure in the LVOT that looked like mitral leaflet tissue originating from the anterior mitral leaflet. This structure had chordae tendineae-like structures attached to the left ventricular surface of the anterior mitral leaflet and had interconnection to the chordae tendineae. When hooked by its free edge, the structure was opened like a parachute and occluded the LVOT. Simultaneously, the anterior mitral leaflet was retracted into the LVOT. No clefts were found in the anterior mitral leaflet. The structure was excised completely, and septal myectomy was performed. The left atrium was opened, and the mitral valve was seen to be almost normal, with a mild friction lesion of the anterior 


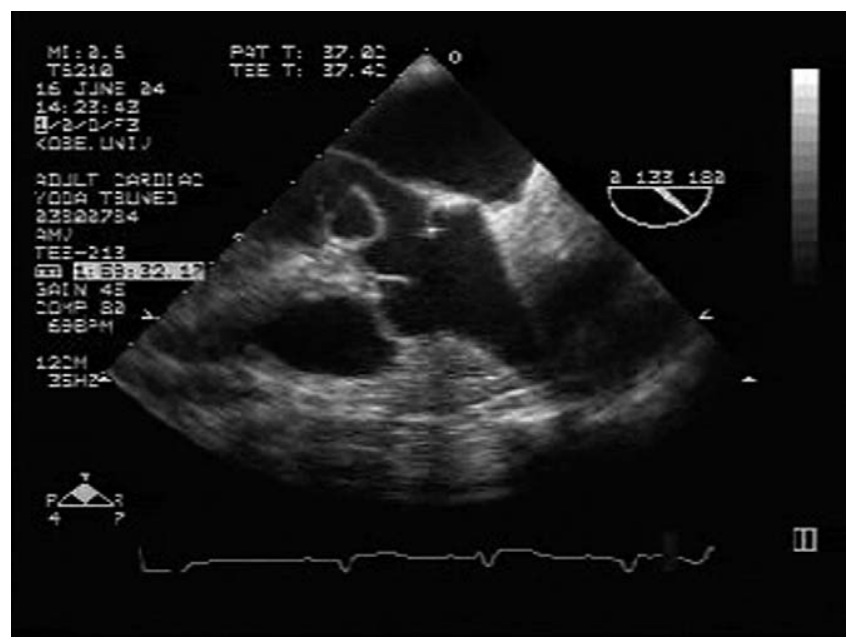

Figure 1. Transesophageal echocardiogram showed parachutelike structure in LVOT.

leaflet. No regurgitation was found after a 28-mm annuloplasty ring (Physio-ring; Edwards Lifesciences, Irvine, Calif) was sutured to the annulus. Aortic valve replacement with a bioprosthetic valve (porcine bioprosthesis valve, $23 \mathrm{~mm}$; Edwards Lifesciences) was performed. No pressure gradient across the LVOT and no mitral insufficiency were documented after surgery. According to histologic examination, the specimen was valve tissue. An echocardiogram 3 months after surgery did not demonstrate any residual LVOT obstruction or mitral insufficiency (Figure 2).

\section{Discussion}

Accessory mitral valve causing LVOT obstruction was first described by McLean and colleagues ${ }^{1}$ in 1963 . Two thirds of instances of this pathologic entity are associated with other congenital cardiac anomalies, and symptoms thus would develop in the early childhood period. Among adults, most patient who underwent surgery have had a presentation of LVOT obstruction. However, no reports have noted mitral insufficiency associated with isolated accessory mitral valve. ${ }^{4,5}$ The membrane insertion of the accessory mitral valve is usually attached to aortomitral continuity; with respect to the chordae tendineae-like structure of the accessory mitral valve, however, many variations have been reported, such as the anterior mitral valve chordae $(n=16 / 32)$, anterior papillary muscle $(\mathrm{n}=14 / 32)$, anterior mitral leaflet valve $(\mathrm{n}=$ $9 / 32)$, left ventricular wall $(\mathrm{n}=7 / 32)$, accessory papillary muscle $(n=4 / 32)$, and interventricular septum $(5 / 32) .{ }^{2,3}$ In our case,
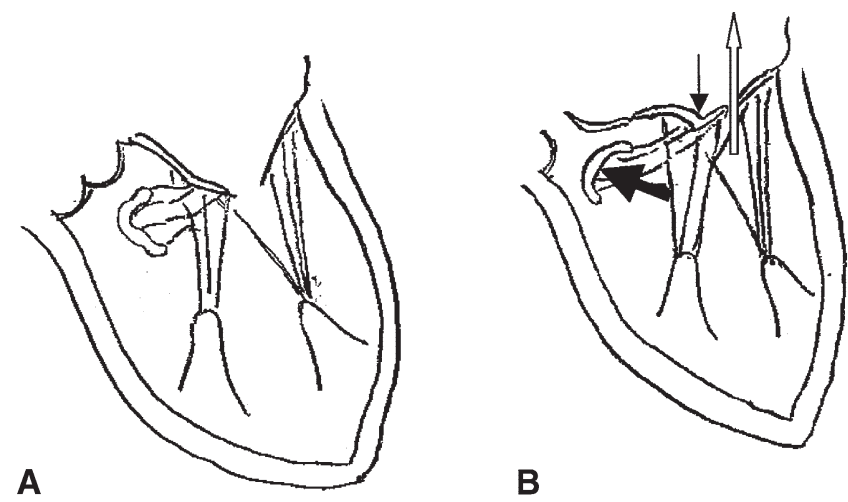

B

Figure 2. A, Diastole. Chordae tendineae-like structure of accessory mitral valve attached to anterior mitral leaflet with interconnection to chordae tendineae. B, Systole. Accessory mitral valve retracted to LVOT and obstruction (black arrow). Anterior mitral leaflet tethered (small arrow) by chordae tendineae-like structure of accessory mitral valve, causing mitral insufficiency (white arrow).

mitral insufficiency had been assumed preoperatively to be caused by a cleft on the lateral portion of the anterior mitral leaflet. The systolic traction of the parachutelike accessory valve leaflet that rendered the anterior mitral leaflet retracted into the LVOT probably yielded the rare phenomenon of LVOT obstruction with mitral insufficiency (Figure 2).

In conclusion, we report a case of accessory mitral valve that caused both LVOT obstruction and mitral insufficiency. Our patient underwent surgery of excision of the accessory mitral valve, septal myectomy, and mitral annuloplasty.

\section{References}

1. McLean LD, Culligan JA, Kane DJ. Subaortic stenosis due to accessory tissue on the mitral valve. J Thorac Cardiovasc Surg. 1963;45:382-7.

2. Prifti E, Bonacchi M, Bartolozzi F, Frati G, Leacche M, Vanini V. Postoperative outcome in patients with accessory mitral valve tissue. Med Sci Monit. 2003;9:RA146-53.

3. Marasini M, Zannini L, Ussia GP, Pinto R. Discrete subaortic stenosis: incidence, morphology and surgical impact of associated subaortic anomalies. Ann Thorac Surg. 2003;75:1763-8.

4. Costa J, Almeida J, Barreiros F, Sousa R. Accessory mitral valve as cause of left ventricular obstruction in adult. J Thorac Cardiovasc Surg. 2003;125:1531-2.

5. Rovner A, Thanigaraj S, Perez JE. Accessory mitral valve in an adult population: The role of echocardiography in diagnosis and management. J Am Soc Echocardiogr. 2005;18:494-8. 